\title{
Does digital X-ray radiogrammetry have a role in identifying patients at increased risk for joint destruction in early rheumatoid arthritis?
}

Kristina Forslind ${ }^{1,2^{*}}$, Johan Kälvesten ${ }^{3,4,5}$, Ingiäld Hafström ${ }^{6}$ and Björn Svensson ${ }^{1,2}$, for for the BARFOT Study Group

\begin{abstract}
Introduction: The aim of this study was to investigate the role of hand bone mineral density (BMD) loss analyzed with digital X-ray radiogrammetry (DXR) in early rheumatoid arthritis (RA) as a predictor for progression of joint damage.

Methods: In 379 patients with early RA, baseline and one-year hand BMD was measured with DXR and the hand bone loss ( $\mathrm{HBL}$ ) was analyzed using the smallest detectable change (HBLsdc) and tertiles (HBLtertiles). Joint damage in hands and feet were scored according to the Sharp van der Heijde (SHS) method at baseline and at one, two, five and eight years. At the same time-points Disease Activity Score (DAS28) was calculated and functional disability assessed. Rheumatoid factor (RF) and antibodies against cyclic citrullinated peptides (anti-CCP) were analyzed at baseline.
\end{abstract}

Results: Sixty-six percent of the patients had hand BMD loss in the first year of RA determined by HBLsdc and 65\% by HBLtertiles. Radiographic progression after two, five and eight years was associated with hand bone loss defined by HBLsdc. By HBLtertiles there were significant associations at all time-points except at eight years. The change in DXR at one year (ChDXR 1 yr $)$ correlated significantly and inversely with the change in SHS (ChSHS) at two, five and eight years. Multivariate analysis showed that only change in SHS during the first year and the presence of anti-CCP were independent predictors of long-term progressive joint damage. If radiographic scores were not included, DXR-BMD loss was an independent predictor. Patients with great bone loss by HBLtertiles had significantly more often high disease activity after two years. However, neither bone loss by HBLsdc or HBLtertiles nor by $C_{\text {ChXR }}$ wr was an independent predictor of remission after two, five and eight years.

Conclusions: This study confirms previous reports of an association of decrease in DXR-BMD during the first disease year with progression of radiographic joint damage over an extended period of time. This association was independent in a regression model only when radiological findings were excluded suggesting a possible predictive role of DXR-BMD in clinical practice when radiographic evaluation is not available. However, further studies are required before this can be established.

\section{Introduction}

Rheumatoid arthritis (RA) is a progressive autoimmune disease characterized by inflammatory activity in the joints, synovial sheets of tendons and bursae as well as extra-articular manifestations such as vasculitis and serositis [1-3]. The increased amount of pro-inflammatory cytokines mediates osteoclast activation, which in turn provokes joint destruction [4].

Both the disease and its drug treatment can cause systemic bone loss and also a periarticular disease-related osteoporosis [5]. The periarticular bone loss in hands is an early feature of RA and may precede erosions [6,7]. As

\footnotetext{
* Correspondence: kforslind@hotmail.com

'Section of Rheumatology, Department of Medicine, Helsingborg Hospital,

Södra Vallgatan 5, 25187 Helsingborg, Sweden

Full list of author information is available at the end of the article
}

(C) 2012 Forslind et al.; licensee BioMed Central Ltd. This is an open access article distributed under the terms of the Creative Commons 
periarticular demineralization and joint damage are both related to imbalance in osteoclast and osteoblast activity, measures of hand bone loss may be a marker for active deterioration of bone and a predictor of subsequent erosive joint damage.

Radiogrammetry was introduced in the sixties for assessment of skeletal status, using various measures of the cortical bone on conventional hand radiographs. The diaphysis of the second metacarpal of the hand was often selected for radiogrammetry. Measurements of the total and medullar width of the bone can be used to calculate different indices and to consecutively quantify changes of cortical bone [8].

The availability of digital images provides the opportunity for quantitative measurements of radio-geometric features and offers a refinement for radiogrammetry $[9,10]$. Digital X-ray radiogrammetry (DXR) is a technique that uses automated image analyses of standard hand radiographs, either in digital or conventional analog format, to estimate bone mineral density (DXR-BMD) $[8,11,12]$. DXR was first introduced into clinical practice in 1999 for osteoporosis assessment. Several studies have shown that this technique has a potential to predict progressive joint damage in RA [13-15].

The heterogeneity of the RA disease and the need for rapid adjustment of disease management puts high requirements on markers for disease progress. The currently available predictors for poor outcome are not perfect and there is a need for improved decision support. The aim of this study was to investigate the potential of hand BMD loss analyzed with DXR to predict progression of joint damage in patients with early RA followed for up to eight years.

\section{Materials and methods Patients}

BARFOT (Better Anti-Rheumatic FarmakOTherapy) is a multicenter observational study (six centers in southern Sweden) of patients with recent (disease duration < one year) onset RA satisfying the 1987 American College of Rheumatology (ACR) classification criteria [6]. Eight hundred and thirty nine (839) patients were consecutively enrolled into the BARFOT study [16] between 1993 and 1999. The patients were between 18 and 80 years of age. The present study comprised the 379 patients who had radiographs available at baseline and one-year follow up, which were suitable for DXR-BMD measurement. Of those with accessible and readable radiographs, four patients were excluded due to improper positioning of the hand. During the observation period, patients were treated according to clinical judgment by their rheumatologist, except for 166 patients participating in a randomized low-dose glucocorticoid study [17].

\section{Radiographic evaluation}

Radiographs of hands and feet were taken at study entry (baseline) and after one, two, five and eight years. At two years radiographs were available for 355 patients, at five years for 288 patients and at eight years for 240 patients. Radiographic damage was scored according to the Sharp van der Heijde score (SHS) [18] which includes hands and feet. A total SHS range 0 to 448 , consisting of erosion score (E score) range 0 to 280 and joint space narrowing score (JSN score) range 0 to 168. An increase of 1 unit means one new pathologic change - E or JSN. Two trained readers, who were blind for treatment and clinical data, read the films in chronological order.

Radiographic progression was defined as a SHS above the smallest detectable change (sdc), which was 5.8, calculated by the formula described by Bruynesteyn et al. [19].

\section{Hand BMD measurements}

BMD of the hands was measured by applying DXR, at baseline and after one year, to the same radiographs of hands that were used for radiographic scoring. The analogue X-ray films were digitized using a Vidar Diagnostic Pro plus, 300 dpi, 12 bit (VIDAR Systems Corp., Herndon, VA, USA). DXR-BMD was measured on the digitized images by dxr-online (Sectra, Linköping, Sweden). DXR is a computerized version of the traditional technique of radiogrammetry [20]. The technique has been described in detail previously $[8,21]$. In short, this method provides a BMD estimate in $\mathrm{g} / \mathrm{cm}^{2}$ based on an automated analysis of the geometry and texture of the cortical bone of the three middle metacarpals.

When radiographs for both hands were available, the mean BMD was used in the analyses to maximize accuracy of the BMD loss measurement.

\section{Hand bone loss}

Hand bone loss (HBL) was defined as present or not present if the one year change in DXR-BMD was more than $0.0048 \mathrm{~g} / \mathrm{cm}^{2}\left(4.8 \mathrm{mg} / \mathrm{cm}^{2}\right)$, the smallest detectable change (sdc) [21] or not (HBLsdc) and as great, moderate or no/small if the one year change in DXR-BMD was within the upper, medium or lower tertiles (HBLtertiles). Changes in HBL are calculated in relation to baseline values.

\section{Clinical evaluations}

Clinical assessments were performed at baseline, three and six months, and one, two, five and eight years. Disease activity was assessed by the Disease Activity Score calculated on 28 joints (DAS28) [22]. High disease activity is defined as a DAS28 $>5.1$, moderate $>3.2 \leq 5.1$ and low $\leq 3.2$ [23]. The European League against Rheumatism (EULAR) definition of remission, a DAS28 $<2.6$, was used [24]. 
Acute phase reactions were measured by erythrocyte sedimentation rate (ESR, $\mathrm{mm} / \mathrm{h}$ ) and C-reactive protein (CRP, $\mathrm{mg} / \mathrm{L}$ ), according to standard laboratory methods. Patients' estimated general health (GH) was assessed by a 0 to 100 $\mathrm{mm}$ horizontal visual analogue scale (VAS) where 0 is best and 100 worst.

Rheumatoid factor (RF) and antibodies against cyclic citrullinated peptides (anti-CCP) were analyzed at baseline. Functional disability was assessed using the Swedish version of the Stanford Health Assessment Questionnaire (HAQ) [25]. The HAQ score ranges from 0 to 3, where a higher score indicates a higher degree of disability.

\section{Statistics}

Statistical analyses were performed using SPSS version 17.0 statistical software. All significance tests were twotailed and conducted at the 0.05 significance level. To test the differences between groups, the Mann-Whitney U-test or the independent $t$-test was used for continuous variables, and the chi ${ }^{2}$-test for proportions. The Wilcoxon matched pairs test was used to compare changes of a variable over time. Spearman's correlation test was used to assess the relationships between two continuous variables.

The inter- and intra-observer reliability was assessed by the intra-class correlation coefficient (ICC) (absolute agreement, two-way mixed model) for status and change scores at baseline and two years.

Univariate analyses were performed by score tests and multiple logistic regression analyses were performed including variables with a statistical significance in the score test of $\mathrm{p}<0.1$.

\section{Ethics committees}

All patients gave their informed consent and the ethical committees in Göteborg: Gbg Ö 282-01; Lund: LU 39801; Linköping: LI 01-263; Karolinska Institutet: KI 02-075 approved the study.

\section{Results}

\section{Baseline characteristics of the patients}

Demographic and clinical characteristics at baseline for the participating 379 patients are shown in Table 1. Fiftyseven percent of the patients had no erosions at baseline.

There were no significant differences in baseline characteristics between these 379 patients having and the 460 patients lacking radiographs suitable for DXR-analyses at baseline and one year (data not shown).

\section{DXR - BMD}

At baseline, the mean (SD) DXR-BMD was 574(94) mg/ $\mathrm{cm}^{2}$ and the mean (SD) Z-score -0.10 (1.13). The mean (SD) change in DXR-BMD from baseline to one year $\left(\mathrm{ChDXR}_{1 \mathrm{yr}}\right)$ was $-16(19) \mathrm{mg} / \mathrm{cm}^{2}\left(-1.3 \mathrm{mg} / \mathrm{cm}^{2} / \mathrm{month}\right)$
Table 1 Demographic and baseline clinical characteristics for the $\mathbf{3 7 9}$ patients.

\begin{tabular}{|c|c|c|c|}
\hline & Mean (SD) & Number (\%) & \\
\hline \multicolumn{2}{|c|}{ Age at inclusion, years } & $57(15)$ & \\
\hline \multicolumn{2}{|c|}{ Disease duration, months } & $6.3(3.2)$ & \\
\hline \multicolumn{2}{|c|}{ Women } & & $241(64)$ \\
\hline \multicolumn{2}{|c|}{ Anti CCP positive } & & $210(61)$ \\
\hline \multicolumn{2}{|c|}{ RF positive } & & $221(65)$ \\
\hline \multicolumn{2}{|c|}{ DAS28 } & $5.07(1.2)$ & \\
\hline \multicolumn{2}{|l|}{ ESR } & $38(26)$ & \\
\hline \multicolumn{2}{|l|}{ CRP, mg/L } & $37(38)$ & \\
\hline \multicolumn{2}{|c|}{$\mathrm{HAQ}, 0-3$} & $0.97(0.61)$ & \\
\hline \multicolumn{2}{|c|}{ Total Sharp score (SHS) } & $4.0(8.2)$ & \\
\hline \multicolumn{2}{|c|}{ Erosion score (ES) } & $1.7(3.8)$ & \\
\hline \multicolumn{2}{|c|}{ Joint space narrowing score (JSN) } & $2.3(5.2)$ & \\
\hline \multicolumn{2}{|c|}{ Prednisolone } & & $1876(50)$ \\
\hline \multirow[t]{6}{*}{ DMARDS } & None & & $77(20)$ \\
\hline & Methotrexate & & $155(41)$ \\
\hline & Sulfasalazine & & $102(27)$ \\
\hline & Other DMARD & & $44(12)$ \\
\hline & Combination & & $1(0)$ \\
\hline & Biologics & & $0(0)$ \\
\hline
\end{tabular}

Anti-CCP, antibodies against cyclic citrullinated peptides; CRP, C-reactive protein; DAS28, Disease Activity Score calculated on 28 joints; DMARDS, disease modifying anti-rheumatic drugs; ESR, erythrocyte sedimentation rate; $\mathrm{HAQ}$, Health Assessment Questionnaire; N, number; RF, rheumatoid factor; SD, standard deviation.

and mean (SD) change in Z- score was $-0.27(0.35)$. A cumulative probability plot illustrates $\mathrm{ChDXR}_{1 \mathrm{yr}}$ (Figure 1 ). Figure 1 shows that the lower tertile corresponds to a one year change in BMD of -5 and the upper a change of $-18 \mathrm{mg} / \mathrm{cm}^{2}$.

\section{Correlations between decreased DXR-BMD and increased radiographic damage scores}

$\mathrm{ChDXR}_{1 y \mathrm{r}}$ correlated significantly and inversely with ChSHS at two, five and eight years with the correlation coefficients $-0.295,-0.215$ and -0.239 , respectively, all $\mathrm{p}<0.001$.

\section{Hand bone loss was associated with increase in radiographic damage score}

The mean ChSHS at two, five and eight years was at all time-points significantly greater in the group of patients with hand bone loss by HBLsdc. The association was most pronounced at two years (Table 2).

Similarly, the mean ChSHS at these time points was significantly greater in patients with hand bone loss according to HBLtertiles. A post hoc pair wise analysis showed that, at two years, the groups of patients with great and moderate HBL had significantly greater ChSHS than the group with no/small HBL while at five and eight years this was the case only for the great $\mathrm{HBL}$ group (Table 3). 


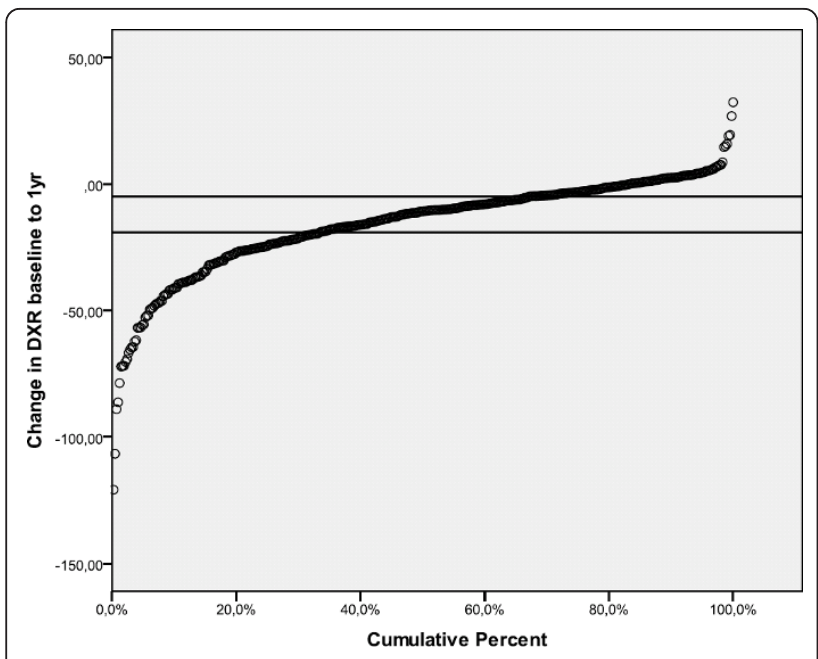

Figure 1 Cumulative percent plot of the change $(\mathrm{mg} / \mathrm{cm} 2)$ in DXR from baseline to one year. Reference lines denote tertiles -upper tertile- a change of $-18 \mathrm{mg} / \mathrm{cm}^{2}$; lower tertile - a change of $-5 \mathrm{mg} / \mathrm{cm}^{2}$. DXR, digital X-ray radiogrammetry.

The differences in mean ChSHS over time between the groups of patients with HBLsdc and HBLtertiles are illustrated in Figures 2 and 3.

\section{Hand bone loss was associated with radiographic progression}

Radiographic progression from baseline was seen in 25\% of the patients after one year, in $41 \%$ of the patients at the follow-up visit at two years, in $60 \%$ at five years and in $61 \%$ at eight years.

At the same time-points $43 \%, 38 \%, 37 \%$ and $36 \%$ of the patients, respectively, still had no erosions. The inter- and intra-observer reliability was 0.94 and 0.99 , respectively.

Radiographic progression after two, five and eight years was associated with HBL defined by HBLsdc (Table 4). By HBLtertiles there were significant associations at all time-points except at eight years (Table 5). The association was most pronounced after two years, when $49 \%$ of the patients with HBL by HBLsdc had radiographic progression and analyzed by HBLtertiles also 49\% (54\% of the patients with great and $44 \%$ with moderate HBL) had radiographic progression $(\mathrm{p}<0.001)$.

Table 2 Change in radiographic scores (SHS) in presence or absence of hand bone loss.

\begin{tabular}{lllllllll}
\hline \multicolumn{1}{c}{ HBLsdc } \\
\cline { 2 - 8 } & \multicolumn{1}{l}{ No hand bone loss } & \multicolumn{4}{l}{ Hand bone loss } & Diff. \\
\hline Change in SHS & Mean & SD & $N$ & Mean & SD & $N$ & $p$ \\
ChSHS2yr & 4.31 & 8.36 & 113 & 10.81 & 15.48 & 242 & 0.001 \\
ChSHS5yr & 11.82 & 15.36 & 89 & 21.49 & 26.59 & 199 & 0.003 \\
ChHSHS8yr & 13.31 & 16.91 & 81 & 23.58 & 28.34 & 159 & 0.005 \\
\hline
\end{tabular}

ChSHS, change in SHS; HBLsdc, hand bone loss smallest detectable change; $\mathrm{N}$, number; SD, standard deviation; SHS, Sharp van der Heijde Score; yr, year.

\section{The performance of DXR-BMD as a predictor of radiographic progression}

Univariate analyses by score tests of demographic and clinical variables possibly associated with radiographic progression were performed. Since the predictive ability of a change in DXR-BMD over one year is under study, not only baseline data but also information obtained up to one year after baseline could have useful predictive value and must, therefore, be taken into consideration. The following variables were univariately associated with radiographic progression, at two, five and eight years: $C_{D X R_{1 y r}}$, HBLsdc, HBLtertiles, $\mathrm{ChSHS}_{1 \mathrm{yr}}$, presence of erosions $\mathrm{bl}_{\mathrm{b}}$, anti- CCP as well as number of swollen joints ${ }_{1 y r}$; at two years: $\mathrm{DAS}_{28} 8_{1 \mathrm{yr}}, \mathrm{GH}_{1 \mathrm{yr}}, \mathrm{ESR}_{\mathrm{bl}}, \mathrm{ESR}_{1 \mathrm{yr}}, \mathrm{HAQ}_{1 \mathrm{yr}}$ and $\mathrm{CRP}_{1 \mathrm{yr}}$; at five years: DAS28 $8_{1 \mathrm{yr}}, \mathrm{ESR}_{\mathrm{bl}}, \mathrm{ESR}_{1 \mathrm{yr},} \mathrm{CRP}$ bl and $\mathrm{CRP}_{1 \mathrm{yr}}$; and at 8 years: tender joints $\mathrm{s}_{\mathrm{bl}}$ and tender joints $\mathrm{s}_{1 \mathrm{yr}}$.

Age, disease duration, gender, smoking, baseline diseasemodifying anti-rheumatic drug (DMARD) and glucocorticoid treatment as well as baseline DXR-BMD (including Z scores) were not univariately associated with radiographic progression at any time point.

The positive predictive values (PPVs) of the presence of $\mathrm{HBL}$ by $\mathrm{HBL}_{\mathrm{sdc}}$ for radiological progression at two, five and eight years (prevalence of $41 \%, 60 \%$ and $61 \%$, respectively) were $49 \%, 65 \%$ and $61 \%$. The corresponding PPVs of anti- CCP were $50 \%, 73 \%$ and $70 \%$; of erosions bl $^{56 \% \text {, }}$ $73 \%$ and $73 \%$; and of ChSHS1yr (above median) were $76 \%$, $81 \%$ and $83 \%$.

ChDXR1yr and the other variables significantly associated with radiographic progression in the univariate analysis were put into multiple logistic regression analyses with radiographic progression at two, five, and eight years as dependent variable. Table 4 shows the two-year result where $\mathrm{ChSHS}_{1 \mathrm{yr}}$ and anti-CCP proved to be independent predictors of radiographic progression which also was the result for five years. At eight years $\mathrm{ChSHS}_{1 \mathrm{yr}}$, anti-CCP and the number of tender joints $\mathrm{bl}_{\mathrm{bl}}$ and tender joints $_{1 \mathrm{yr}}$ were independent predictors.

Since scoring of radiographs is infrequently performed in clinical practice, models excluding radiographic scores $\left(\mathrm{ChSHS}_{1 \mathrm{yr}}\right)$ were also done. Then $\mathrm{ChDXR}_{1 \mathrm{yr}}$ independently predicted radiographic progression at two years in addition to anti- CCP, number of swollen joints $s_{1 y r}$ and presence of erosions $\mathrm{bl}_{\mathrm{bl}}$ (Table 6). In the prediction models at five and eight years $\mathrm{ChDXR}_{1 \mathrm{yr}}$ did not attain statistical significance $(p=0.083$ and 0.073 , respectively). At five years, erosions $\mathrm{bl}_{\mathrm{b}}$, anti-CCP, number of swollen joints ${ }_{1 \mathrm{yr}}$, and $\mathrm{CRP}_{1 \mathrm{y}}$, were independent predictors and at eight years anti-CCP, number of swollen joints syr $_{1 \mathrm{r}}$ and number of tender joints at baseline and one year.

HBLsdc and HBLtertiles were univariately associated with radiographic progression at all time-points, but did not significantly contribute to prediction in the multivariate models (data not shown). 
Table 3 Change in radiographic scores (SHS) in patients with great, moderate or no/small hand bone loss.

\begin{tabular}{|c|c|c|c|c|c|c|c|c|c|c|}
\hline & \multicolumn{10}{|c|}{ HBLtertiles } \\
\hline & \multicolumn{3}{|c|}{ Great bone loss } & \multicolumn{3}{|c|}{ Moderate bone loss } & \multicolumn{3}{|c|}{ No/small bone loss } & \multirow{2}{*}{$\begin{array}{l}\text { Diff. } \\
\text { p }\end{array}$} \\
\hline & Mean & SD & $\mathbf{N}$ & Mean & SD & $\mathrm{N}$ & Mean & SD & $\mathrm{N}$ & \\
\hline \multicolumn{11}{|c|}{ Change in SHS } \\
\hline ChSHS2yr & 12.84 & 18.74 & 119 & 8.90 & 11.33 & 118 & 4.44 & 8.37 & 118 & 0.001 \\
\hline ChSHS5yr & 23.96 & 29.64 & 103 & 19.03 & 23.09 & 91 & 12.01 & 15.32 & 94 & 0.005 \\
\hline ChSHS8yr & 26.04 & 30.65 & 81 & 21.17 & 26.09 & 75 & 13.46 & 16.74 & 84 & 0.011 \\
\hline
\end{tabular}

ChSHS, change in SHS; HBL, hand bone loss; N, number; SD, standard deviation; SHS, Sharp van der Heijde Score; yr, year.

The best model predicting radiographic progression was obtained at the two- year follow-up visit. In this model, including radiographic scores Nagelkerke R2 was 77\% and $91 \%$ of the patients correctly classified while the corresponding figures were $36 \%$ and $75 \%$ in the model excluding radiographic scores (Table 6). After five years, R2 was $52 \%$ and $38 \%$ and the proportion of correct classifications was $79 \%$ and $75 \%$ in the models with and without radiographic scoring, respectively. The corresponding figures for eight years were $44 \%$ and $30 \%$ and $73 \%$ and $72 \%$, respectively.

Replacing $\mathrm{ChDXR}_{1 \mathrm{yr}}$ with Z-scores to account for age related bone loss did not improve prediction (data not shown).

\section{DXR -BMD and clinical outcome}

Hand bone loss and degree of disease activity after two, five and eight years

Cross tabulation of hand bone loss by HBLsdc and degree of disease activity showed no significant differences in degree of disease activity after two, five and eight years in patients with or without bone loss (data not shown). However, patients with great bone loss by

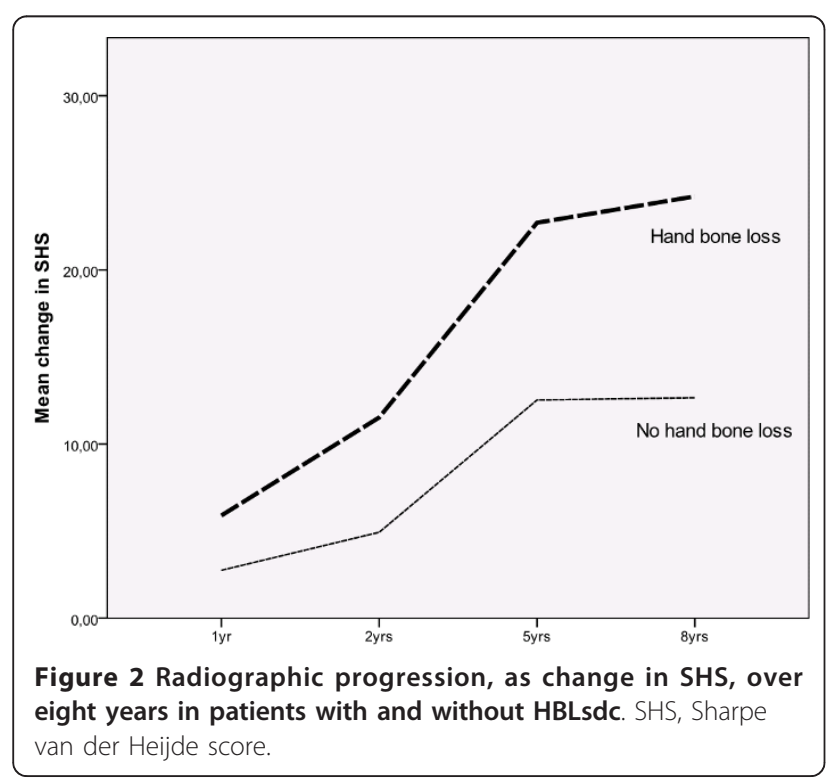

HBLtertiles had significantly high disease activity more often after two years compared with patients with moderate or low activity (16\% versus $5 \%$ and $6 \%$, respectively, $\mathrm{p}=0.009$ ).

\section{Hand bone loss and remission}

In patients with HBL by HBLsdc, remission was significantly less frequent after two years than in patients without (38\% versus $49 \%, \mathrm{p}=0.037$ ) but not after five ( $43 \%$ versus $39 \%, \mathrm{p}=0.49$ ) or eight years $(40 \%$ versus $48 \%, \mathrm{p}=0.24)$.

In patients with great bone loss by HBLtertiles, remission was less frequent after two years than in patients with moderate or no/small bone loss (34\% versus $41 \%$ and $50 \%$, respectively, $\mathrm{p}=0.045)$. No significant differences were seen after five years (42\% versus $46 \%$ and $39 \%$, respectively, $\mathrm{p}=0.59$ ) or eight years $(36 \%$ versus $46 \%$ and $47 \%$, respectively, $\mathrm{p}=0.27$.)

\section{Hand bone loss as a predictor of remission aftertwo, five}

\section{and eight years}

Although DXR-BMD showed a univariate association with remission at two and eight years, neither bone loss by HBLsdc or HBLtertiles nor by $C_{\text {DXR }}$ yr $_{1}$ was an independent predictor of remission after two, five and

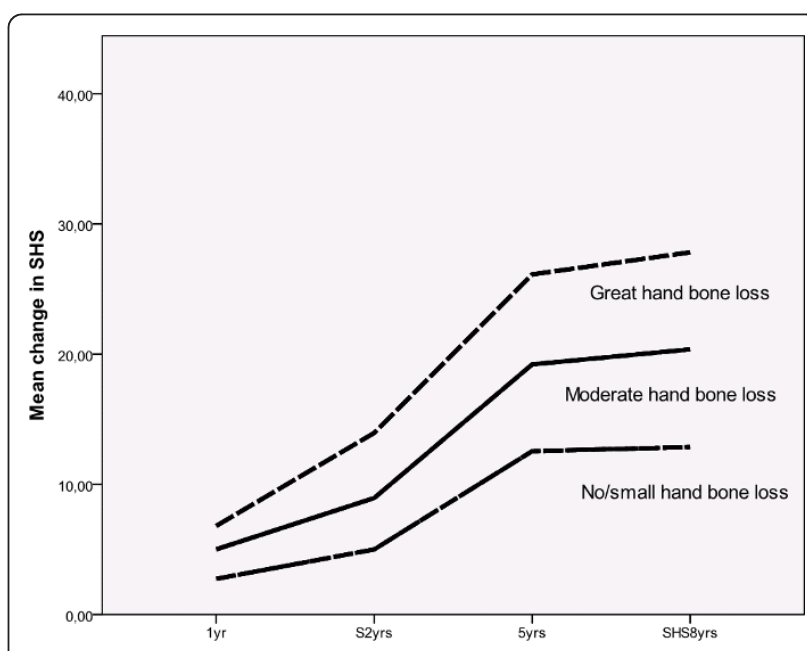

Figure 3 Radiographic progression, as change in SHS, over eight years in patients with and without HBLtertiles. SHS, Sharpe van der Heijde score. 
Table 4 Radiographic progression in presence or absence of hand bone loss.

\begin{tabular}{llll}
\hline & $\begin{array}{l}\text { HBLsdc } \\
\text { No hand bone } \\
\text { loss } \\
\mathbf{N}(\%)\end{array}$ & $\begin{array}{l}\text { Hand bone } \\
\text { loss }\end{array}$ & Diff. \\
$\begin{array}{l}\text { Radiographic } \\
\text { progression }\end{array}$ & $27(24)$ & $\mathbf{p}$ \\
\hline 2 years & $43(48)$ & $118(49)$ & 0.001 \\
5 years & $42(52)$ & $129(65)$ & 0.008 \\
8 years & $105(66)$ & 0.033 \\
\hline
\end{tabular}

HBLsdc, hand bone loss smallest detectable change; $N$, number.

eight years in models including and excluding $\mathrm{x}$-ray scores (data not shown).

\section{Discussion}

In this study on 379 patients with early RA who were followed for eight years we have studied the potential of HBL during the first year measured by DXR to predict radiographic joint damage progression after two, five and eight years.

In accordance with previous studies, HBL above SDC was significantly associated with radiographic joint damage. This was the case also when HBL was defined by tertiles as great, moderate or no/small.

In the early stage of the disease the patients had bone loss more often than they had radiographic progression. Thus, after one year HBL was present in $68 \%$ of the patients while progressive joint damage was seen in only $25 \%$. With time radiographic progression increased to more than $60 \%$, which is in agreement with the report by Güler-Yüksel et al. [26], who showed bone loss after one year in $68 \%$, progressive joint damage in $18 \%$ and after four years progressive joint damage in $30 \%$. The explanation for this difference is that localized loss of BMD predates erosions and joint destruction $[27,28]$.

Change in DXR-BMD between baseline and one year correlated significantly and inversely with change in SHS at all time-points. This is in agreement with previous studies $[13,14,29]$. In an observational study, Stewart et al. showed that measurement of HBL over one year, using DXR, correlated with erosive changes in patients with

Table 5 Radiographic progression in patients with great, moderate or no/small hand bone loss.

\begin{tabular}{lllll}
\hline & $\begin{array}{l}\text { HBLtertiles } \\
\text { Great } \\
\text { bone loss }\end{array}$ & $\begin{array}{l}\text { Moderate } \\
\text { bone loss }\end{array}$ & $\begin{array}{l}\text { No/small } \\
\text { bone loss }\end{array}$ & Diff. \\
\hline $\begin{array}{l}\text { Radiographic } \\
\text { progression }\end{array}$ & $\mathrm{N}(\%)$ & $\mathrm{N}(\%)$ & $\mathrm{N}(\%)$ & $\mathrm{p}$ \\
2 years & $64(54)$ & $52(44)$ & $29(25)$ & 0.001 \\
5 years & $72(70)$ & $54(59)$ & $46(49)$ & 0.011 \\
8 years & $57(70)$ & $46(61)$ & $44(52)$ & 0.060 \\
\hline
\end{tabular}

$\mathrm{HBL}$, hand bone loss; $\mathrm{N}$, number. early RA at four years follow-up [29] and Hoff et al. also showed that patients with hand BMD loss at one year had more radiographic damage at five and ten years in comparison with patients without HBL [30]. However, in these studies, the correlations between hand BMD and joint damage were found to be small suggesting that the predictive ability of HBL for joint damage may be limited. This notion is further supported by the modest PPVs of HBL for joint damage found in the present study.

The change in SHS from baseline to one year and the presence of anti-CCP, but not change in DXR-BMD, were the only independent predictors of radiographic progression at two years. This is in line with the BeSt study reporting that hand BMD loss as a risk factor for further radiographic damage is largely overridden by change in SHS measured over one year [26]. This implies that the first year change in DXR-BMD does not add to the therapeutic decision if radiographic scores are available. However, in clinical practice, scoring radiographs is not frequently performed, as it is a time-consuming method requiring special training.

Therefore, in the absence of radiographic scores, DXRBMD, which today may be easily accessible in clinical practice, might be a helpful predictor. Indeed, the present data show that in the absence of radiographic scoring the change in DXR-BMD was an independent predictor of radiographic progression, significant at two years, but not at five and eight years.

In the present study, change in SHS over the first year was the single best predictor of further radiological progression. This predictor attained the highest PPVs and contributed highly to create the best regression model for predicting radiological outcome at two years, in which also the presence or absence of baseline erosions, anti-CCP and number of swollen joints after one year were independent predictors. By this model Nagelkerke $\mathrm{R}^{2}$ was $77 \%$ and $91 \%$ of the patients could be correctly classified. Thus, change in SHS over the first year is indeed a promising predictor for use at this stage of the disease. However, it would be ideal if reliable predictors could be identified at an earlier stage of the disease.

Ongoing studies including measuring changes in DXRBMD over shorter time periods, for example, three and six months, are awaited with great interest. Recently a study with six months data on hand BMD loss was published [31]. Here DXR-BMD loss was measured from baseline to six months in 80 patients with early (mean disease duration 11 month) undifferentiated arthritis. They found that great BMD loss was associated with RA development after one year. It should be noted that the cut-off value for 'great bone loss' was considerably higher than that used in the present study ( $\geq 2.5$ versus $1.5 \mathrm{mg} / \mathrm{cm}^{2} /$ month).

It has been suggested that treatment with biologics may decelerate the development of erosions more than 
Table 6 Multiple logistic regression of possible independent predictors of radiographic progression at two years.

\begin{tabular}{|c|c|c|c|c|c|c|c|c|}
\hline \multirow[b]{3}{*}{ Change DXR 1 yr } & \multicolumn{4}{|c|}{ Model with $\mathrm{x}$ - ray scores ${ }^{\mathrm{a}}$} & \multicolumn{4}{|c|}{ Model without $\mathrm{x}$ - ray scores ${ }^{\mathrm{b}}$} \\
\hline & \multirow{2}{*}{$\frac{\text { OR }}{1.001}$} & \multicolumn{2}{|c|}{$95 \% \mathrm{Cl}$} & \multirow{2}{*}{$\begin{array}{l}\mathbf{p} \\
.956\end{array}$} & \multirow{2}{*}{$\frac{\text { OR }}{0.971}$} & \multicolumn{2}{|c|}{$95 \% \mathrm{Cl}$} & \multirow{2}{*}{$\frac{\mathbf{p}}{.001}$} \\
\hline & & .0 .974 & 1.029 & & & 0.955 & 0.988 & \\
\hline Change SHS 1 yr & 2.667 & 2.027 & 3.511 & .000 & & & & \\
\hline Erosions at baseline & .666 & .262 & 1.691 & .392 & 2.592 & 1.486 & 4.519 & .001 \\
\hline Anti- CCP & 3.475 & 1.332 & 9.066 & .011 & 3.132 & 1.701 & 5.766 & .001 \\
\hline Number of swollenjoints $1 \mathrm{yr}$ & 1.086 & .931 & 1.267 & .296 & 1.129 & 1.021 & 1.248 & .018 \\
\hline DAS28 1 yr & 1.220 & .645 & 2.307 & .541 & 1.181 & .791 & 1.764 & .417 \\
\hline General health 1 yr & .990 & .961 & 1.021 & .527 & .997 & .979 & 1.016 & .761 \\
\hline ESR baseline & .999 & .979 & 1.018 & .886 & .991 & .979 & 1.004 & .178 \\
\hline ESR 1 yr & 1.014 & .980 & 1.050 & .415 & 1.005 & .982 & 1.030 & .665 \\
\hline HAQ $1 \mathrm{yr}$ & 1.327 & .570 & 3.092 & .512 & 1.079 & .608 & 1.916 & .795 \\
\hline CRP 1 yr & .974 & .929 & 1.020 & .261 & 1.006 & .980 & 1.032 & .656 \\
\hline Constant & .014 & & & .000 & .060 & & & .001 \\
\hline
\end{tabular}

${ }^{a} R^{2}=77 \% .91 \%$ correct classification. ${ }^{b} R^{2}=36 \% .75 \%$ correct classification. Anti-CCP, antibodies against cyclic citrullinated peptides; Cl, confidence interval; CRP, C-reactive protein; DAS28, Disease Activity Score calculated on 28 joints; DXR, digital X-ray radiogrammetry; ESR, erythrocyte sedimentation rate; HAQ, Health Assessment Questionnaire; OR, odds ratio; SHS, Sharp van der Heijde Score; yr, year.

it reduces HBL [32]. However, since the present study was performed before the introduction of biologics, this issue could not be further addressed.

Loss of bone measured by HBLsdc and HBLtertiles was more frequent in patients with high disease activity and in patients not in remission after two years but not in later phases of the disease. HBL did not come out as an independent predictor of clinical outcome in multiple regression analyses. In 145 patients from the BeSt study, where change in hand BMD by DXR was investigated, an increase in BMD occurred mostly in patients with continuous remission by the EULAR criterion [33]. However, continuously low disease activity did not appear to provide less loss in hand BMD than continuously high disease activity. Therefore, although reduction of BMD is a consequence of inflammation, DXR-BMD is not a suitable tool for predicting disease activity in the future.

A shortcoming of this study was that, at several sites, the technical conditions at acquisition of X-rays were such that BMD could not be measured for some patients which led to the loss of several patients from the study, but the included patients did not differ in baseline characteristics from those not included. Furthermore, the patients with early RA in this study fulfilled the ACR 1987 criteria, whereas patients with very early RA who presented with limited clinical symptoms were not included until they fulfilled the criteria. This means that we have no data, neither of radiographic damage nor of bone mineral density from the very early phase of RA.

\section{Conclusions}

To conclude, the present study confirms previous studies reporting an association of change in DXR-BMD over the first year of RA disease with progression of radiographic joint damage over an extended period of time. However, the change in DXR-BMD was not an independent predictor of radiographic joint damage progression. Instead, change in SHS from baseline to one year was a strong predictor of radiographic progression both after two years and after longer follow-up visits at five and eight years. On the other hand, when radiological findings were excluded the association was independent. This suggests a possible predictive role of DXR-BMD in clinical practice when radiographic evaluation is not available. However, since the association was significant only after the follow-up at two years and the PPVs of bone loss for radiological progression were quite small, further studies are required before this can be established. Further studies on DXR may focus on the diagnosis of early RA also considering sex- and age-related DXR data that define a threshold value to discriminate possible patients with RA. In particular, studies with a shorter interval between measurements of DXR-BMD are encouraged to evaluate its predictive power in early RA, ideally before joint damage has become identified radiographically.

\section{Abbreviations \\ ACR: American College of Rheumatology; Anti-CCP: anti-cyclic citrullinated proteins; BARFOT: Better Anti-Rheumatic FarmacoTherapy; BMD: bone mineral density; ChDXR: change in DXR; ChSHS: change in SHS; CRP: C- reactive protein; DAS: Disease Activity Score; DXR: digital X-ray radiogrammetry; E: erosions; ESR: erythrocyte sedimentation rate; EULAR: European League against Rheumatism; GH: general health; HAQ: Health Assessment Questionnaire; HBL: hand bone loss; ICC: intra-class correlation coefficient; JSN: joint space narrowing; PPV: positive predictive value; RA: rheumatoid arthritis; RF: rheumatoid factor; sdc: smallest detectable change; SHS: Sharp van der Heijde Score; VAS: visual analogue scale.}

\section{Authors' contributions}

All authors contributed to the study design, acquisition of data, analysis and interpretation of data, and manuscript preparation. BS contributed with statistical analysis. All authors read and approved the final manuscript. 


\section{Competing interests}

JK is an employee of Sectra Imtec AB. KF has received honoraria from Abbott and Bristol-Myers Squibb, not related to this study. All other authors declare they have no competing interests.

\section{Acknowledgements}

This study was supported by grants from the Swedish Rheumatism Association, the Thelma Zoégas foundation in Helsingborg, and Stiftelsen för Rörelsehindrade i Skåne.

The BARFOT Study Group: Sofia Ajeganova, Maria Andersson, Valentina Bala, Stefan Bergman, Kristina Forslind, Ingiäld Hafström, Catharina Keller, Ido Leden, Bengt Lindell, Ingemar Petersson, Christopher Schaufelberger, Björn Svensson, Maria Söderlin, Annika Teleman, and Jan Theander.

\section{Author details}

'Section of Rheumatology, Department of Medicine, Helsingborg Hospital, Södra Vallgatan 5, 25187 Helsingborg, Sweden. ${ }^{2}$ Section of Rheumatology, Institution of Clinical Science, University Hospital, Klinikgatan 15, 22242 Lund, Sweden. ${ }^{3}$ Section of Radiology, Department of Medicine and Health Sciences, University Hospital, 58185 Linköping, Sweden. ${ }^{4}$ Center for Medical Image Science and Visualization (CMIV), Linköping University, 58183 Linköping, Sweden. ${ }^{5}$ Sectra Imtec AB, Teknikringen 20, 58330 Linköping, Sweden. ${ }^{6}$ Rheumatology Unit, Karolinska Institutet, Karolinska University Hospital, 14186 Huddinge, Sweden.

Received: 23 March 2012 Revised: 31 August 2012

Accepted: 25 September 2012 Published: 15 October 2012

\section{References}

1. Papadopoulos IA, Katsimbri P, Katsaraki A, Temekonidis T, Georgiadis A, Drosos AA: Clinical course and outcome of early rheumatoid arthritis. Rheumatol Int 2001, 20:205-210.

2. Schett G: Erosive arthritis. Arthritis Res Ther 2007, 9:S2.

3. Goldring SR: Periarticular bone changes in rheumatoid arthritis: pathophysiological implications and clinical utility. Ann Rheum Dis 2009 68:297-299.

4. Hirayama T, Danks L, Sabokbar A, Athanasou NA: Osteoclast formation and activity in the pathogenesis of osteoporosis in rheumatoid arthritis. Rheumatology 2002, 41:1232-1239.

5. Böttcher J, Peil A, Heinrich B, Lehmann G, Petrovitch A, Hansch A, Heyne JP, Mentzel HJ, Malich A, Hein G, Kaiser WA: Digital radiogrammetry as a new diagnostic tool for estimation of disease-related osteoporosis in rheumatoid arthritis compared with pQCT. Rheumatol Int 2005, 25:457-764.

6. Arnett FC, Edworthy SM, Bloch DA, McShane DJ, Fries JF, Cooper NS, Healey LA, Kaplan SR, Liang MH, Luthra HS, Medsger TA, Mitchell DM Jr, Neustadt DH, Pinals RS, Schaller JG, Sharp JT, Wilder RL, Hunder GG: The American Rheumatism Association 1987 revised criteria for the classification of rheumatoid arthritis. Arthritis Rheum 1988, 31:315-324.

7. Brower AC: Use of the radiograph to measure the course of rheumatoid arthritis. The gold standard versus fool's gold. Arthritis Rheum 1990, 33:316-324.

8. Rosholm A, Hyldstrup L, Baeksgaard L, Grunkin M, Thodberg HH: Estimation of bone mineral density by digital X-ray radiogrammetry: theoretical background and clinical testing. Osteoporos Int 2001, 12:961-969.

9. James MF, Heald G, Shorter JH, Turner RA: Joint space measurement in hand radiographs using computerized image analysis. Arthritis Rheum 1995, 38:891-901.

10. Sharp JT, Gardner JC, Bennett EM: Computer-based methods for measuring joint space and estimating erosion volume in the finger and wrist joints of patients with rheumatoid arthritis. Arthritis Rheum 2000, 43:1378-1386.

11. Jörgensen JT, Andersen PB, Rosholm A, Bjarnason NH: Digital X-ray radiogrammetry: a new appendicular bone densitometric method with high precision. Clin Physiol 2000, 20:330-335.

12. Ward KA, Cotton J, Adams JE: A technical and clinical evaluation of digital X-ray radiogrammetry. Osteoporos Int 2003, 14:389-395.

13. Hoff M, Haugeberg G, Kvien TK: Hand bone loss as an outcome measure in established rheumatoid arthritis: 2-year observational study comparing cortical and total bone loss. Arthritis Res Ther 2007, 9:R81
14. Forslind K, Boonen A, Albertsson K, Hafström I, Svensson B, for the BARFOT Study Group: Hand bone loss measured by digital X-ray radiogrammetry is a predictor of joint damage in early rheumatoid arthritis. Scand J Rheumatol 2009, 38:431-438.

15. Güler-Yüksel M, Allaart CF, Goekoop-Ruiterman YPM, de Vries-Bouwstra JK, van Groenendael JHLM, Mallee C, de Bois MHW, Breedveld FC, Dijkmans BAC, Lems WF: Changes in hand and generalized bone mineral density in patients with recent-onset rheumatoid arthritis. Ann Rheum Dis 2009, 68:330-336.

16. Svensson B, Schaufelberger C, Teleman A, Theander J: Remission and response to early treatment of RA assessed by the Disease Activity Score. BARFOT study group. Better Anti-rheumatic Farmacotherapy. Rheumatology 2000, 39:1031-1036.

17. Svensson B, Boonen A, Albertsson K, van der Heijde D, Keller C, Hafström I: Low-dose prednisolone in addition to the initial disease-modifying antirheumatic drug in patients with early active rheumatoid arthritis reduces joint destruction and increases the remission rate: a two-year randomized trial. Arthritis Rheum 2005, 52:3360-3370.

18. Van der Heijde D: How to read radiographs according to the Sharp/van der Heijde method. J Rheumatol 2000, 27:261-263.

19. Bruynesteyn $K$, Boers M, Kostense P, van der Linden S, van der Heijde D: Deciding on progression of joint damage in paired films of individual patients. Ann Rheum Dis 2005, 64:179-182.

20. Barnett $E$, Nordin B: The radiological diagnosis of osteoporosis: a new approach. Clin Radiol 1960, 11:166-174.

21. Hoff M, Dhainaut A, Kvien TK, Haugeberg G: Short-time precision assessed with digital X-ray radiogrammetry in healthy individuals and rheumatoid arthritis patients. Ann Rheum Dis 2008, 67(Suppl 2):563.

22. Prevoo ML, van't Hof MA, Kuper $H H$, van Leeuwen $M A$, van de Putte $L B$, van Riel PL: Modified disease activity scores that include twenty-eightjoint counts. Development and validation in a prospective longitudinal study of patients with rheumatoid arthritis. Arthritis Rheum 1995, 38:44-48.

23. van Gestel AM, Haagsma CJ, van Riel PL: Validation of rheumatoid arthritis improvement criteria that include simplified joint counts. Arthritis Rheum 1998, 41:1845-1850.

24. Prevoo MLL, van Gestel AM, van't Hof MA, van Rijswijk MH, van de Putte LBA, van Riel PLCM: Remission in a prospective study of patients with rheumatoid arthritis. American Rheumatism Association preliminary remission criteria in relation to the disease activity score. $\mathrm{Br} J$ Rheumatol 1996, 35:1101-1105.

25. Ekdahl C, Eberhardt K, Andersson SI, Svensson B: Assessing disability in patients with rheumatoid arthritis. Use of a Swedish version of the Stanford Health Assessment Questionnaire. Scand J Rheumatol 1988 17:263-271.

26. Güler-Yüksel M, Bijsterbosch J, Allaart CF, Meulenbelt I, Kroon HM, Watt I, Lems WF, Kloppenburg M: Accelerated hand bone mineral density loss is associated with progressive joint damage in hands and feet in recentonset rheumatoid arthritis. Arthritis Res Ther 2010, 12:R96.

27. Haugeberg G, Lodder MC, Lems WF, Uhlig T, Örstavik RE, Dijkmans BAC, Kvien TK, Woolf AD: Hand cortical bone mass and its associations with radiographic joint damage and fractures in 50-70 year old female patients with rheumatoid arthritis: cross sectional Oslo-Truro-Amsterdam (OSTRA) collaborative study. Ann Rheum Dis 2004, 63:1331-1334.

28. Forsblad-d'Elia H, Carlsten H: Bone mineral density by digital X-ray radiogrammetry is strongly decreased and associated with joint destruction in long-standing Rheumatoid Arthritis: a cross-sectional study. BMC Musculoskeletal Disorders 2011, 12:242.

29. Stewart A, Mackenzie LM, Black AJ, Reid DM: Predicting erosive disease in rheumatoid arthritis. A longitudinal study of changes in bone density using digital X-ray radiogrammetry: a pilot study. Rheumatology 2004, 43:1561-1564.

30. Hoff M, Haugeberg G, Ödegård S, Syversen S, Landewé R, van der Heijde D, Kvien TK: Cortical hand bone loss after 1 year in early rheumatoid arthritis predicts radiographic hand joint damage at 5 and 10-year follow-up. Ann Rheum Dis 2009, 68:324-329.

31. de Rooy DPC, Kälvesten J, Huizinga TWJ, van der Helm-van Mil AHM: Loss of metacarpal bone density predicts RA development in recent-onset arthritis. Rheumatology (Oxford) 2012, 51:1037-1041.

32. Hoff M, Kvien TK, Kälvesten J, Algulin J, Elden A, Haugeberg G: Adalimumab therapy reduces hand bone loss in early rheumatoid 
arthritis: explorative analyses from the PREMIER study. Ann Rheum Dis 2009, 68:1171-6

33. Dirven L, Güler-Yüksel M, de Beus WM, Ronday HK, Speyer I, Huizinga TW, Dijkmans BA, Allaart CF, Lems WF: Changes in hand bone mineral density and the association with the level of disease activity in patients with rheumatoid arthritis: bone mineral density measurements in a multicenter randomized clinical trial. Arthritis Care Res 2011, 63:1691-1699.

doi:10.1186/ar4058

Cite this article as: Forslind et al: Does digital X-ray radiogrammetry

have a role in identifying patients at increased risk for joint destruction in early rheumatoid arthritis? Arthritis Research \& Therapy 2012 14:R219.

Submit your next manuscript to BioMed Central and take full advantage of:

- Convenient online submission

- Thorough peer review

- No space constraints or color figure charges

- Immediate publication on acceptance

- Inclusion in PubMed, CAS, Scopus and Google Scholar

- Research which is freely available for redistribution

Submit your manuscript at www.biomedcentral.com/submit 